\title{
$3 \quad$ History as a Laboratory: Materials and Methods
}

A central premise of this book is that we can use history as a 'laboratory' to test theories with relevance beyond particular time-space contexts. This is an analytical approach to history, one where the goal is not simply to tell the story of the past, to describe conspicuous events, or to construct time series of certain phenomena, but rather to develop and test hypotheses. ${ }^{1}$ The study of disasters lends itself particularly well to this end for three main reasons. First, hazards, disasters, and their effects are generally well documented in historical written records across the globe, allowing us to trace their social, economic, and cultural dimensions over time. Second, environmental hazards occur at multiple scales - both spatial and temporal - and are met with divergent responses and impacts across these scales, allowing us to make comparisons and hence offer a counterpoint to the limitations of descriptive analysis. ${ }^{2}$ Third, where we lack written information on the hazards themselves, independent of their impact, we can use other forms of knowledge such as scientific proxies as a baseline.

Using history as a laboratory to better understand disasters, however, makes practical demands of us as historians: we need suitable measures and methods to understand hazards and their effects, we can work only with what is physically available to us, and we must do so without losing sight of the critical approach to sources that forms the cornerstone of sound historical scholarship. This chapter discusses these issues: the process of identifying and interpreting sources, of reconstructing and measuring disasters, and of analyzing them in the historical laboratory. The rest of the chapter is split into two parts: the first deals with sources of data and the second with methods.

\footnotetext{
${ }^{1}$ Van Bavel \& Curtis, 'Better Understanding Disasters.' $\quad{ }^{2}$ See Section 3.2.3.
} 


\subsection{Historical Sources}

\subsubsection{Types of Historical Sources}

The types of historical sources available to research hazards, disasters, and their aftermath are deeply intertwined with the characteristics of the societies producing them. This book is mainly interested in historical written records. This is not to say that non-written sources are irrelevant for the study of disasters and history - far from it - but rather that written sources provide the qualitative and quantitative basis for investigation into the kind of questions that our historical laboratory aims to address. ${ }^{3}$ This section will introduce the types of sources available prior to the widespread instrumental recording of environmental variability as well as modern instrumental records. While we are concerned first and foremost with the hazard-society nexus, we also cover the types of sources and datasets available to provide information on hazards. Indeed, an almost ubiquitous feature of the historical record, at least in the pre-industrial period, is that the very same sources hold information on both hazards and their societal impacts - as outlined in Table 3.1 - making it difficult to separate one from the other in such a discussion.

For the period before instrumental recording, evidence on hazards and disasters is based on a combination of direct observations and descriptions from contemporaries, and indirect recording of processes and phenomena that were influenced by environmental conditions. This evidence was recorded in a wide range of documents of a narrative and administrative nature, although common to both direct and indirect evidence is the fact that many records were not kept for the primary purpose of systematically recording hazards and disasters but were the product of other (often economic) purposes. ${ }^{4}$

'Direct' documentary source types, where available, should represent the first port of call, although in practice these sources are often not widely available or detailed enough to assemble a comprehensive picture of hazards and disasters. One direct source that has received much attention is English manorial accounts extending back to the early thirteenth century CE (1230 in the case of the Bishopric of Winchester). These sources not only list the quantity of seed and yield for wheat but also make consistent reference to the influence of severe weather conditions on farming activity, providing a continuous series of seasonal climatic

\footnotetext{
${ }^{3}$ For the relevance of non-written sources, see for example Section 3.1.2.

${ }^{4}$ For a good indication about source types, see Pfister \& Brázdil, 'Social Vulnerability'; Nash \& Adamson, 'Recent Advances.'
} 
Table 3.1 Historical documentary evidence for reconstructing hazards and their impacts prior to instrumental recording

\begin{tabular}{|c|c|c|}
\hline Hazard & Associated impacts & Key sources \\
\hline $\begin{array}{l}\text { Precipitation, } \\
\text { floods, } \\
\text { drought }\end{array}$ & $\begin{array}{l}\text { Harvest failures/shortfalls, damage } \\
\text { to structures, loss of capital } \\
\text { goods, malnutrition, mortality }\end{array}$ & $\begin{array}{l}\text { Harvest accounts, phenological } \\
\text { accounts (e.g. dates of } \\
\text { flowering), rogations, burial } \\
\text { records, colonial governmental } \\
\text { records, missionary accounts, } \\
\text { newspapers, private diaries (e.g. } \\
\text { of weather, farming, or more } \\
\text { indirect), ships' logbooks, grain } \\
\text { prices }\end{array}$ \\
\hline $\begin{array}{l}\text { Temperature, } \\
\text { ice/snow } \\
\text { cover }\end{array}$ & $\begin{array}{l}\text { Harvest failures/shortfalls, } \\
\text { malnutrition, mortality }\end{array}$ & $\begin{array}{l}\text { Harvest accounts, missionary } \\
\text { accounts, ships' logbooks, ice- } \\
\text { break accounts, burial records }\end{array}$ \\
\hline $\begin{array}{l}\text { Hurricanes, } \\
\text { cyclones, } \\
\text { typhoons }\end{array}$ & $\begin{array}{l}\text { Inundation of land, harvest failures/ } \\
\text { shortfalls, damage to structures, } \\
\text { loss of capital goods, } \\
\text { malnutrition, mortality }\end{array}$ & $\begin{array}{l}\text { Missionary accounts, colonial } \\
\text { governmental records, private } \\
\text { diaries, ships' logbooks, } \\
\text { chronicles, gazetteers }\end{array}$ \\
\hline $\begin{array}{l}\text { Earthquakes, } \\
\text { volcanic } \\
\text { eruptions, } \\
\text { tsunamis }\end{array}$ & $\begin{array}{l}\text { Damage to structures, loss of } \\
\text { capital goods, mortality }\end{array}$ & $\begin{array}{l}\text { Chronicles, gazetteers, petitions, } \\
\text { historical catalogs (chronologies } \\
\text { of events) }\end{array}$ \\
\hline $\begin{array}{l}\text { Sand drifts, } \\
\text { erosion, } \\
\text { landslides }\end{array}$ & $\begin{array}{l}\text { Land degradation, damage to } \\
\text { structures, loss of capital goods }\end{array}$ & $\begin{array}{l}\text { Rent and tax registers, charters, } \\
\text { bylaws, land books, maps, } \\
\text { reports, eye-witness accounts, } \\
\text { tenant contracts, chronicles, } \\
\text { petitions, newspapers }\end{array}$ \\
\hline Epidemics & Mortality, reduction in fertility & $\begin{array}{l}\text { Burial records, mortmain } \\
\text { accounts, wills and testaments, } \\
\text { ordinances, city accounts, bills of } \\
\text { mortality, plague house/hospital } \\
\text { documentation, medical } \\
\text { treatises, religious tracts, } \\
\text { orphanage records, chronicles }\end{array}$ \\
\hline
\end{tabular}

conditions and their agrarian impacts until the middle of the fifteenth century. ${ }^{5}$ While these sources are invaluable, and indeed have spurred much work on the climate-society nexus in medieval England, ${ }^{6}$ it is rare to have such a direct, consistent, and detailed source at our disposal at that point in time.

\footnotetext{
5 Titow, 'Evidence of Weather'; Titow, 'Le climat.'

${ }^{6}$ Campbell, The Great Transition; Slavin, Experiencing Famine.
} 
Scholars are therefore more frequently drawn to sources such as chronicles, which are much more widely available and at a larger geographical scale - particularly for medieval Europe, but also for early-colonial settings during the sixteenth and seventeenth centuries. Chronicles are books that contain a chronological narrative centered on notable occasions and often mention extraordinary weather events, diseases, and food crises. In some cases these sources represent the only narrative evidence we have on certain events. Secondary works that compile references to hazards and disasters have relied extensively on chronicles, a well-known example being Jean-Noël Biraben's work that compiles 'mentions' of medieval plague outbreaks. ${ }^{7}$ Comparable in nature, but focusing on a specific type of event, are historical catalogs (chronologies of unusual events and their impacts) composed by contemporaries. In Italy, for instance, the first earthquake catalog, based on eye-witness accounts and information from earlier chronicles, was compiled in the late seventeenth century. ${ }^{8}$ Other compilations assembled more recently but based on similar source types include the Mediterranean tsunami catalog, which covers the coast of Greece, Turkey, Syria, Israel, and the Southern Balkans, and extends back into the second millennium BCE. ${ }^{9}$

Parallels in non-Western societies sometimes go back to a more distant past and are frequently more detailed than European chronicles and catalogs. A famous example are the Egyptian Nilometers, specifically constructed to measure the heights of the floods, which were essential for agriculture. These give us an insight into the occurrence of floods and droughts. Roman examples were preserved at Aswan and Luxor; a medieval one can be seen in Cairo. ${ }^{10}$ The Babylonian Astronomical Diaries, another example, not only record unusual natural phenomena, but also give detailed price quotations, allowing analysis of the impact of, for instance, locust invasions on markets in the fourth century BCE. ${ }^{11}$ For China, local gazetteers - recordings of regional history and geography form a valuable source of information. The first gazetteer dates from about 2000 years ago, but, especially during the Ming and Qing periods, thousands of gazetteers on the provincial, prefectural, and county level were compiled, usually by government officials or local scholars. Most gazetteers contain sections devoted to extreme events such as storms and floods; the later ones also give detailed information on the social, political,

\footnotetext{
${ }^{7}$ Biraben, Les hommes et la peste, II. See Section 3.1.3 for an analysis of the pitfalls of such datasets.

${ }^{8}$ Rohr, 'Man and Natural Disaster,' 130.

${ }^{9}$ Maramai, Brizuela \& Graziani, 'The Euro-Mediterranean Tsunami Catalogue.'

${ }^{10}$ Shaw, The Oxford History of Ancient Egypt, 420.

${ }^{11}$ Pirngruber, 'Plagues and Prices: Locusts.'
} 
and economic consequences of such events. Data from gazetteers have, for instance, been used to reconstruct the effects of gender and family relationships on coping strategies during the North China Famine of $1876-79 .^{12}$

Such sources, however, are mostly limited to Western and Central Europe, the Middle East, and East Asia, and elsewhere we are forced to look to other source types. For the pre-industrial period, written source availability is often greatest in areas with histories of colonialism that extend back beyond the late nineteenth century. Thus, recent work on disasters and history of a more global scope has included Southern Africa, ${ }^{13}$ South Asia, ${ }^{14}$ the Caribbean, ${ }^{15}$ and South America. ${ }^{16}$ One source that has proven to be of high value in these areas is the records of missionary societies. Missionaries were usually stationed in one area for a significant length of time and were assiduous recorders of the physical environment as it was crucial to subsistence and transportation, making these documents of particular value for the study of hazards. Moreover, unlike traders and many early-colonial officials, missionaries usually turned their attention beyond the workings of the colonial machine and onto the local population - especially during times of stress. ${ }^{17}$ These sources have been supplemented by newspapers, which sometimes provided regular reference to provincial weather conditions, ${ }^{18}$ and the diaries of hunters, travelers, traders, and explorers, who often reported weather conditions and their perceived impacts on the societies through which they traveled. ${ }^{19}$ All of these sources nevertheless have their own particular biases and must be 'read against the grain' if we are to identify the local voices within the narrative. Changes in source coverage must also be taken into consideration when analyzing developments over the long term. Gaps and silences in colonial records occur for many reasons, and it must be ensured that absence of evidence relating to disasters is not conflated with evidence of absence.

Indirect evidence (or proxy data), often derived from serial administrative sources, also allows us to explore the occurrence, course, and consequences of pre-industrial disasters. In parts of Central Europe, for example, the beginning of the grape and rye harvest was reported each year to the owner of the tithe to facilitate the monitoring and

${ }^{12}$ Edgerton-Tarpley, 'Family and Gender in Famine.'

${ }^{13}$ Hannaford, 'Long-Term Drivers'; Nash et al., 'Seasonal Rainfall Variability.'

${ }^{14}$ Adamson \& Nash, 'Documentary Reconstruction'; Adamson \& Nash, 'Long-Term Variability.'

${ }^{15}$ Berland \& Endfield, 'Drought and Disaster.'

${ }^{16}$ Prieto \& Herrera, 'Documentary Sources from South America.'

${ }^{17}$ See for example Hannaford, 'Pre-colonial South-East Africa.'

${ }^{18}$ Nash et al., 'Seasonal Rainfall Variability.' $\quad{ }^{19}$ Adamson, 'Private Diaries.' 
collection of the crop. The close association between harvest dates and seasonal climatic conditions, however, enables these sources to be used as climatic proxy data. ${ }^{20}$ Evidence on yields can be used as an indicator of food availability and is relatively widely available for Western Europe from the fifteenth century onwards. Price series, usually of dominant bread grains such as wheat or rye, are also frequently used as an indicator for food crisis and famine. One needs to tread carefully when using price series to reconstruct periods of dearth, however, as they are usually limited to more commercial (urban) regions and drawn from institutional accounts, whose prices are not necessarily representative of the rates at which the majority of the population acquired grain. ${ }^{21}$ Accounts (of cities, villages, but also of religious institutions) can also contain references to extreme weather events and/or disease. In Spain and Italy, for example, the Catholic Church organized rogation services (rogativas) in an attempt to bring an end to situations of protracted wet or dry conditions which adversely affected crops. ${ }^{22}$ As the costs of these rituals were borne by the municipality, expenses and receipts for rogations are found in the accounts of ecclesiastical and civic institutions, which can give us an indication of periods of climatic stress. ${ }^{23}$

One of the key indicators of disaster impact (or lack thereof) and recovery is mortality, although this is sometimes challenging to reconstruct. Mortmain registers, stemming from the feudal right of the lord to part of his subjects' inheritance, and similar to the heriots used for England, have recently proved to be very useful for parts of medieval Northwest Europe. ${ }^{24}$ Parish registers, often available there from the sixteenth century and becoming increasingly widespread elsewhere in Europe from the seventeenth century onwards, are best placed to give us an idea of mortality via burial records ${ }^{25}$ while baptismal and marriage records allow us to reconstruct fertility and nuptiality - variables of importance when assessing the demographic impact of crises and of possible recovery. ${ }^{26}$ Burial records also sometimes contain direct references to diseases, and similar references can be found within ordinances, wills, theological and medical treatises, orphanage records, city accounts, and so on. Such data are patchy in early-colonial contexts, and, where

${ }^{20}$ See for example Wetter \& Pfister, 'Spring-Summer Temperatures'; Le Roy Ladurie \& Baulant, 'Grape Harvests.' See also Section 3.2.1.

${ }^{21}$ Walter \& Schofield, 'Famine, Disease and Crisis Mortality.'

22 Rodrigo \& Barriendos, 'Reconstruction.'

${ }^{23}$ Piervitali \& Colacino, 'Evidence of Drought.'

${ }^{24}$ Roosen \& Curtis, 'The "Light Touch."”

25 Curtis, 'Was Plague an Exclusively Urban Phenomenon?'; Alfani, 'Plague in Seventeenth-Century Europe.'

${ }^{26}$ Sella, 'Coping with Famine.' 
they do exist, they often relate to the colonizers rather than the colonized. However, data become much more widely available from the middle of the nineteenth century, in parallel with the rise of censuses and more formalized reports from colonies.

Demographic indicators are not the only variables affording us an idea of impact and recovery. Information on land sales, credit transactions, and criminal cases can all shed light on the severity of a crisis and on the types of coping strategies that were developed. ${ }^{27}$ Of all types of coping strategies, perhaps those most difficult to reconstruct are informal ways of solidarity. In some regions of pre-industrial Europe, poor relief was formalized, and so accounts of poor relief institutions or overseers of the poor can offer insight here. ${ }^{28}$ Still, more informal mechanisms were vital even dominant in some regions - and these are much harder to investigate. Practices linked to common rights, such as gleaning, can often be traced in bylaws, but voluntary practices such as almsgiving are much harder to trace, even though there are indications that it was of huge importance ${ }^{29}$ Such practices are also visible in some colonial accounts, although again one must step out of the ideology and hegemonic discourse of these texts if informal coping mechanisms are to be correctly identified.

From the seventeenth and especially the eighteenth century onwards, more and more sources are at the disposal of historians. This is mainly linked to the fact that states became much stronger from the seventeenth century onwards, coupled with the growth of bureaucratic administration and colonial expansion. Alongside the rise of political economy, cameralism, and physiocracy in the eighteenth century, measurement became essential for increasing 'the wealth of nations.' This also had an effect on the types of sources linked to disasters. The Lisbon earthquake of 1755 is allegedly the first disaster in which the new focus on numbers and statistics came to the fore. The Marquis of Pombal "designed a national survey to discover the causes and origin of the natural disaster, minimize future risks and assess the damage the earthquake had caused." 30 This type of survey was also used when it came to combating disease, as for example in the Rinderpest outbreak in the late-eighteenth-century Southern Netherlands. ${ }^{31}$

27 Campbell, 'Nature as Historical Protagonist.' For land and credit transactions, see Schofield, 'The Social Economy.' For criminality as an indicator, see Vanhaute \& Lambrecht, 'Famine.'

${ }^{28}$ For the Low Countries, see Van Onacker \& Masure, 'Unity in Diversity'; Dijkman, 'Bread for the Poor.' For England, see Hindle, On the Parish?

${ }^{29}$ Marfany, 'Quantifying the Unquantifiable?'; Lambrecht, 'The Harvest of the Poor?'

30 Araújo, 'The Lisbon Earthquake,' 9.

31 As mentioned in Van Roosbroeck \& Sundberg, 'Culling the Herds?' 
Sources originating with the government and its agencies become even more important in the nineteenth and twentieth centuries. One of the major changes throughout this period was the rapid growth in instrumental recording of environmental phenomena, as illustrated in the increase in the coverage of national meteorological networks from 1850 to 2012 in Figure 3.1.

The increased geographical coverage and temporal resolution of these data in turn allow us to pose new questions relating to societal decisionmaking and perceptions during hazardous events. ${ }^{32}$ Important changes were also occurring within colonial administrations and their recordkeeping: during each of the major famines in late-nineteenth-century India, for instance, the colonial authorities installed designated commissions which produced extensive and detailed reports on causes, consequences, and relief policies deemed necessary. ${ }^{33}$ Equally, the more general annual reports compiled by colonial governments across the world provide quantitative and qualitative material with which to assemble chronologies of disasters - particularly relating to disease and famine at regional and local scales, and also to analyze the emergence of new responses to hazards and disasters in newly colonized territories. One example is insurance, which became more and more important (linked to the emergence of a risk society). ${ }^{34}$ Likewise, the increase of newspaper reporting (and in the twentieth century of radio and television broadcasts) that came with the expanding role of the media can yield insights on how disasters unfolded and their aftermath. ${ }^{35}$ Media coverage has proven especially valuable for studies of the perception and 'framing' of disasters. The Lisbon earthquake of 1755 again paved the way as sensational press reports of this catastrophe, reaching audiences throughout Europe, created a novel sense of proximity and public distress over so distant an event. $^{36}$

However, media sources, too, require intensive source critique. Photos, for instance, can depict the same disaster in very different ways. The three photos in Figure 3.2, for example, show very different sides to the Manchurian plague of 1911. They are from an album covering the plague instigated by Dr. Wu Lien-teh, a Chinese doctor who was sent to investigate the struck region and subsequently became an authority in international plague research, as well as the first president of the China Medical Association. Though all three photos are from the same album, they can nevertheless convey a disparate message regarding the situation

\footnotetext{
32 Mauelshagen \& Pfister, 'Vom Klima zur Gesellschaft.'

33 Klein, 'When the Rains Failed.' ${ }^{34}$ Rohland, 'Earthquake versus Fire.'

35 See for example Cohn, 'Cholera Revolts.' ${ }^{36}$ Araújo, 'The Lisbon Earthquake.'
} 

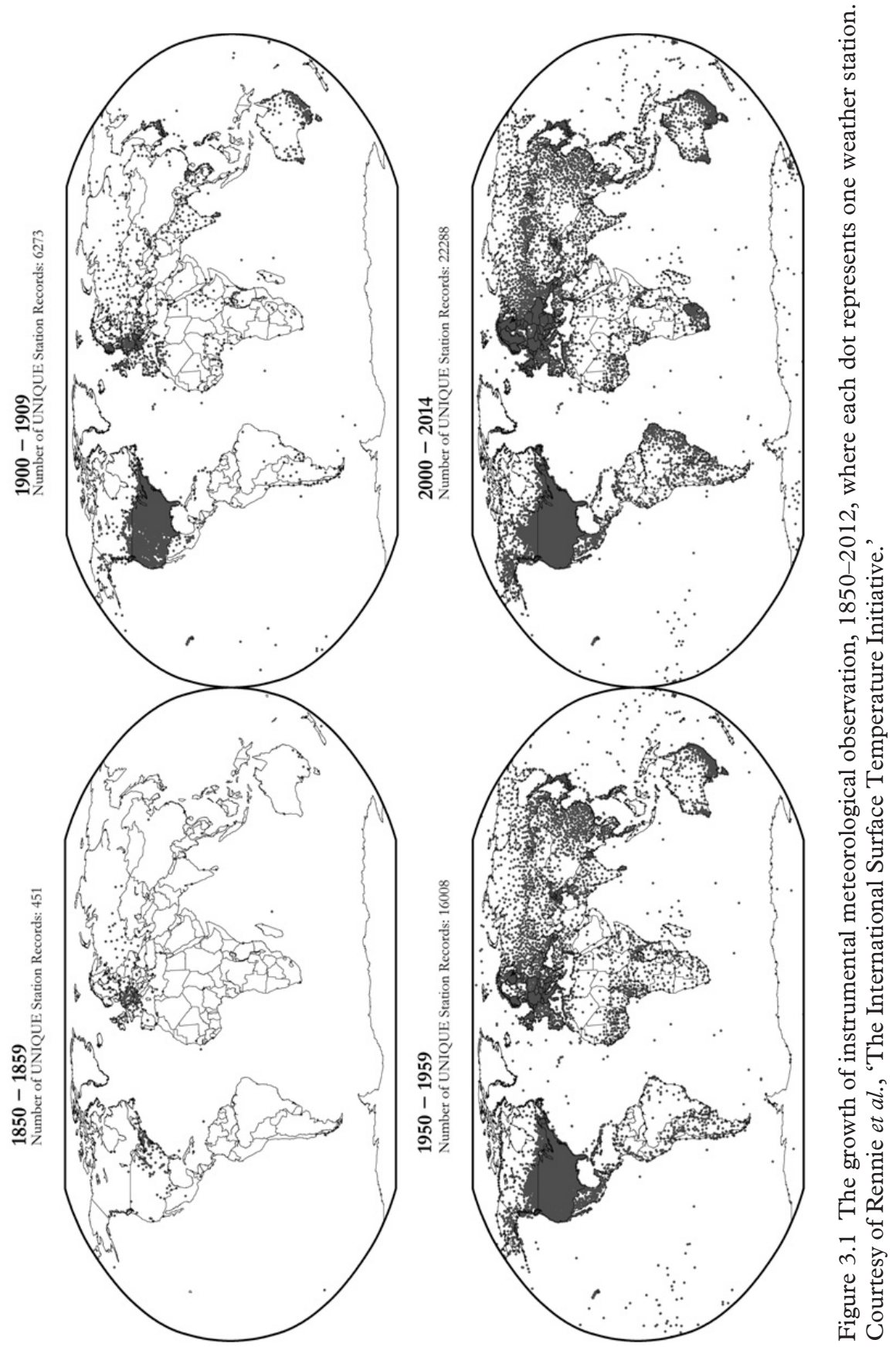

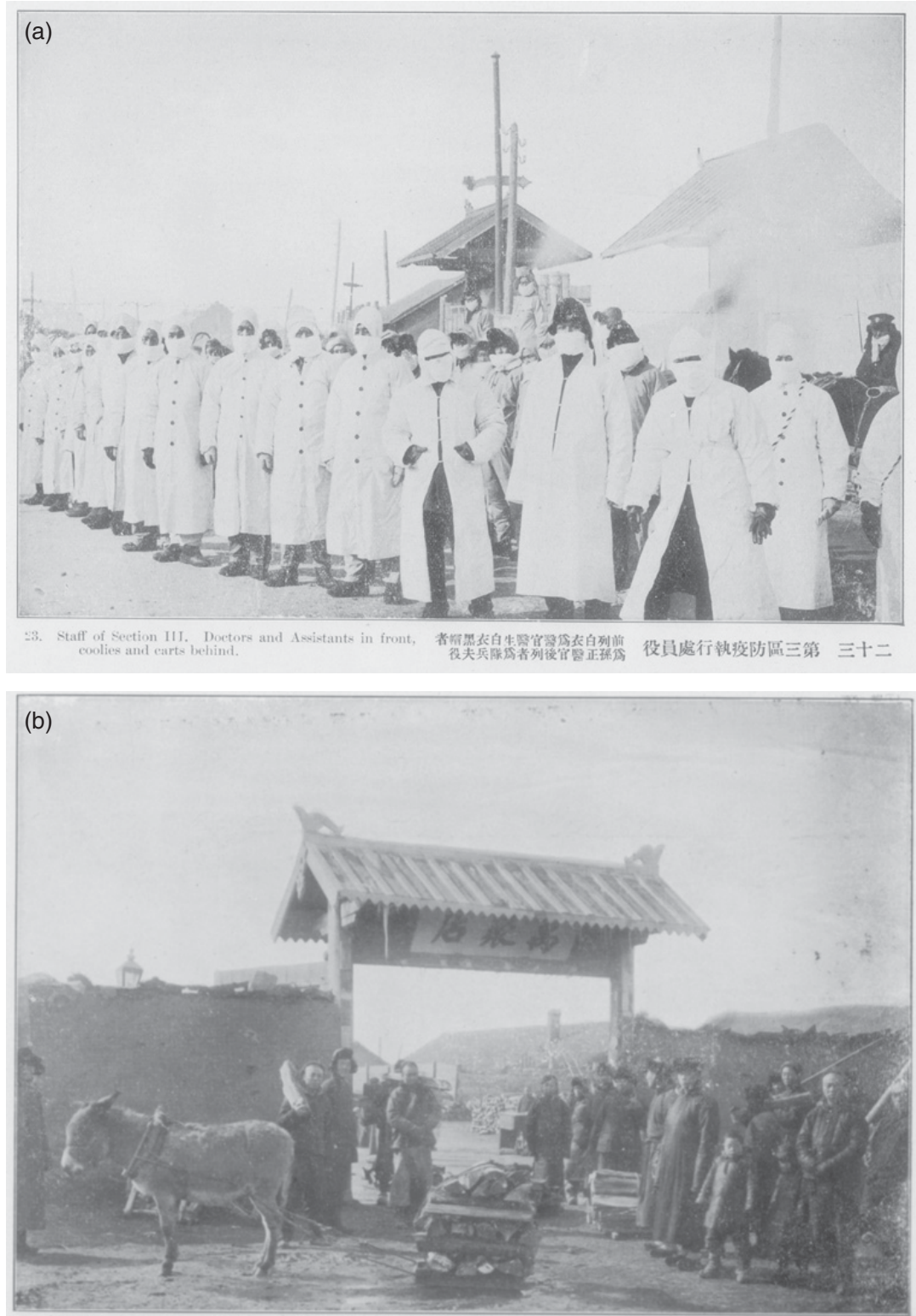

51. Distributing fine-uood to the poor

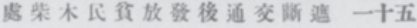

Figure 3.2 Photos of the Manchurian plague of 1911, from an album instigated by Dr. Wu Lien-teh, a famous plague fighter. Courtesy of the Needham Research Institute. 


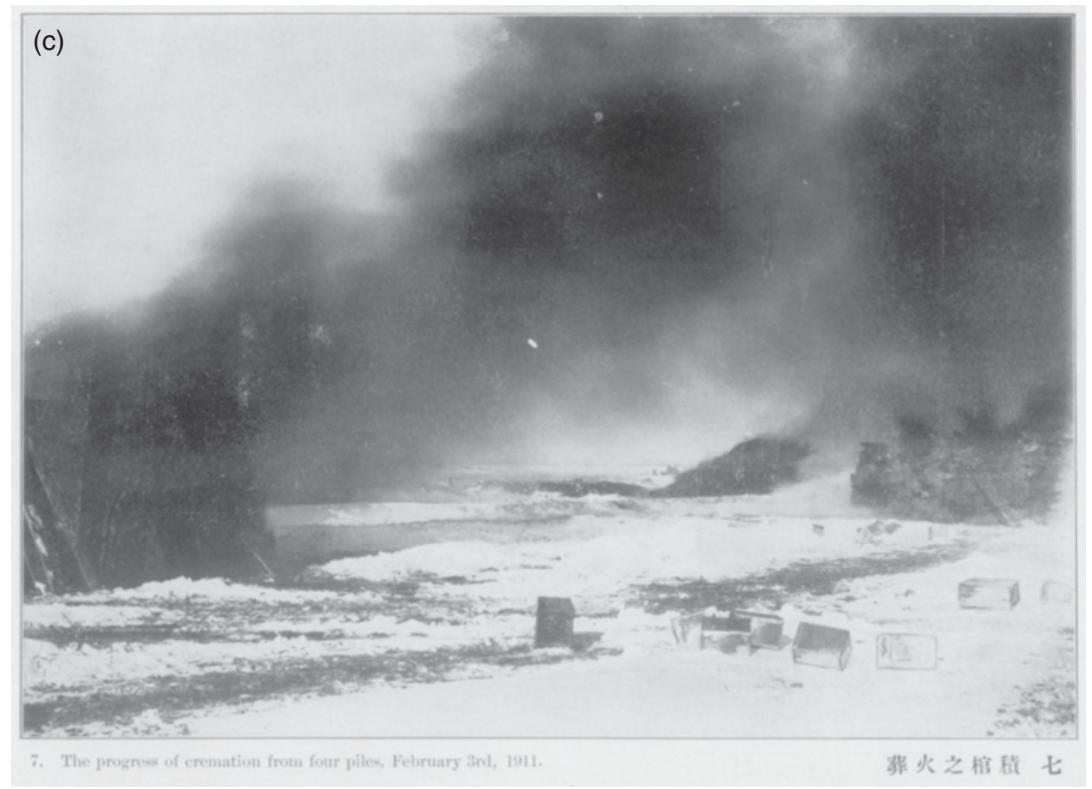

Figure 3.2 (cont.)

in Manchuria. The first shows white coats, white masks, and an overall 'scientific' image of matters entirely under control, legitimizing territorial jurisdiction at a tumultuous time (the final phases of the Qing dynasty). The second photo strengthens this perception of control and legitimacy further by depicting state distribution of firewood to the poor and needy. Contrarily, the third photo shows several piles of plague victims being cremated, conveying the impression that the situation was out of control, and the number of casualties uncontainable.

\subsubsection{Combining Historical Data with Sources from the Natural Sciences}

In recent years, historical research into disasters has grown increasingly interdisciplinary. Disaster historians have started to employ data from the natural sciences, while scholars in the natural and social sciences have begun to use historical data from the types of documentary sources introduced above, as seen most visibly in studies linking past climatic variability to human conflicts, plague outbreaks, and agricultural productivity. ${ }^{37}$ Nevertheless, historical documents hold inherent

${ }^{37}$ See the literature discussed in van Bavel et al., 'Climate and Society.' 
limitations, and, as we will see in the following section, when not viewed critically can lead to spurious conclusions. ${ }^{38}$

One of the most crucial limitations for the study of disasters is that the documents do not necessarily reveal the 'whole' picture: that is to say, they are not a dispassionate or objective reconstruction of the causes and consequences of a disaster. For example, we may see 'crisis situations' described in tax registers, charters, court proceedings, or colonial reports, and yet often these have the potential to be exaggerated for pleas for tax exemptions, subsidies, or charity. Equally, certain aspects of disastrous events can disappear from view in the records. Urban governments often tried to downplay the severity of an epidemic present within the city in order to maintain trading contacts and economic vitality. ${ }^{39}$ Direct references by the urban administration of San Francisco to the earthquake of 1906 were outweighed by references to the fire that ensued. Fire prevention was simply an issue that could be more easily dealt with than earthquakes, and this reveals the selective amnesia connected to the production of documentary sources, even for a twentieth-century event. ${ }^{40}$ Indeed, references to natural events and disasters appear in written sources only when they are relevant for the author or administration. Arable fields could experience serious erosion, but so long as they were cultivated and still provided tithes or taxes, the events would go unremarked upon. As a result, certain types of nature-induced disasters appear much more frequently in sources than others, and some types of societies over-report events, while others remain silent. In the Philippines, typhoons were registered much more accurately than earthquakes and leave accounts as far back as 414 CE, simply because they were more disruptive for humans. ${ }^{41}$ Similarly, storm surges that did not lead to floods badly affecting human habitation or agriculture were less likely to appear in chronicles and diaries, making the distinction between cause and effect rather blurred. ${ }^{42}$

Non-documentary evidence can, therefore, help prevent data hiatus and help uncover source and method biases, which can allow the development of new historical interpretations of hazards and disasters of the past. Accordingly, traditional narratives on the 'late-medieval crisis' have been reinvigorated with new kinds of data in recent times. ${ }^{43}$ Alongside the more traditionally used information on harvests, historians have recently

${ }^{38}$ Van Bavel et al., 'Climate and Society'; Roosen \& Curtis, 'Dangers.' See also Section 3.1.3.

39 Roosen \& Curtis, 'The "Light Touch"'; Wilson Bowers, Plague and Public Health.

40 Rohland, 'Earthquake versus Fire.' $\quad{ }^{41}$ Bankoff, Cultures of Disaster.

42 Soens, 'Resilient Societies.'

43 Campbell, The Great Transition; Pribyl, Farming, Famine and Plague; Bauch \& Schenk, The Crisis of the 14th Century. 
begun to take note of the rapid growth in paleoclimate reconstructions derived from ice-cores, tree-rings, lake sediments, cave speleothems, and other sources. ${ }^{44}$ This has opened up new perspectives on the Little Ice Age, its global scope, and its impacts on society. ${ }^{45}$ The laboratory has also completely revolutionized research into plague over the past decade or so, ${ }^{46}$ and bioarcheological evidence from skeletons in excavated burials sites is providing information on health and living standards that simply cannot be found in documents going back as far as the Middle Ages. ${ }^{47}$

Even better, this evidence is being actively integrated with documentary evidence. For example, the integration of paleoclimatic and written evidence of drought occurrence in sub-Saharan Africa not only provides us with a more complete view of the specific occurrence of drought itself, but also offers the opportunity to analyze why certain droughts led to human disaster while others - perhaps those of even greater severity passed with only minor disturbance. ${ }^{48}$ Equally, more traditional forms of archaeological research into the physical evidence - such as the increasing or declining presence of pottery shards - can provide effective comparative indicators for depopulation between regions - for example after the Black Death. ${ }^{49}$ This is important, given that the geographical or temporal span of our documentary evidence for reconstructing the mortality effects of late-medieval epidemics is often restricted..$^{50}$ More generally, evidence from the natural sciences allows us to go back in time to periods before the widespread production of documents.

Furthermore, natural scientific data can provide an added layer of chronological development and possibly allow more accurate dating of events. For example, the dominant paradigm that disastrous sand drifts in the European coversand belt (stretching from the British Brecklands across continental Europe to Russia) increased only from the late Middle Ages onwards has been falsified by combining historical and geological data. ${ }^{51}$ Reliance on land books, maps, and tax registers grossly exaggerated late-medieval and early-modern sand drifts, since documents of this nature in this part of Europe started to appear only from the fourteenth century onwards. As a result, earlier disasters were neglected and older dunes were dated much younger. Through new

${ }^{44}$ PAGES2k Consortium, 'A Global Multiproxy Database.'

${ }^{45}$ Camenisch \& Rohr, 'When the Weather Turned Bad'; Hannaford \& Nash, 'Climate, History, Society'; Degroot, The Frigid Golden Age.

${ }^{46}$ Little, 'Plague Historians'; Bolton \& Clark, 'Looking for Yersinia pestis'; Green, 'Taking "Pandemic" Seriously.'

${ }^{47}$ DeWitte, 'The Anthropology of Plague.'

${ }^{48}$ Hannaford \& Nash, 'Climate, History, Society.' $\quad{ }^{49}$ Lewis, 'Disaster Recovery.'

${ }^{50}$ Alfani \& Murphy, 'Plague and Lethal Epidemics,' 318.

${ }^{51}$ Derese et al., 'A Medieval Settlement'; De Keyzer, "All We Are”; Pierik et al., 'Controls.' 
techniques such as optically stimulated luminescence (OSL) dating, which dates when quartz particles became covered and were no longer exposed to sunlight, different inland dune sites can be dated more accurately. As a result, it has become clear that earlier disastrous drift sands had occurred more often than had previously been believed, and the later medieval ones relatively less often, with consequences for earlier explanatory models focusing on land reclamation or population pressure on resources. ${ }^{52}$

While offering great potential for the study of disasters and history, data from the natural sciences still require a critical assessment similar to that made by historians working with documentary material. The contextualization of data from the natural sciences is important for discerning the significance of the overall effect that a scientific indicator has on either a human society or a broader ecosystem. For example, in geomorphology every event of sand re-sedimentation is considered vital, with every dated layer given the same weight and importance when determining drift sand phases. ${ }^{53}$ Yet some dunes are made up of thick layers of sand, deposited in relatively swift events, while other dunes are formed by a sequence of thin layers taking centuries to develop. It goes without saying that not all of these phases, with their varying extents and chronologies, have the same impact on human society or even on dune formation. ${ }^{54}$ Equally, paleoclimate proxy data vary enormously in their geographical coverage and temporal resolution, so while many long-duration tree-ring chronologies of seasonal or annual resolution have been produced from the middle and high latitudes of Eurasia and North America, it is much more difficult to identify such growth increments across much of the tropics due to basic differences in climatological conditions. Natural scientific data may also have undergone statistical processing and modeling in order to make composite datasets at large geographical scales. The increasing numbers of climate reconstructions in particular regions, for example, have led to the production of what are known as climate field reconstructions. This has enabled composite time series of temperature, precipitation, and atmospheric pressure to be derived across regions, continents, and even hemispheres. ${ }^{55}$ However, a degree of caution must be applied when using these sources to study hazards within a particular location, for they tend to be weighted to those locations in which data density is greatest (for example, Northwest Europe). Efforts to better define regional historical climate variability have also extended to Southern Africa and South America through the construction of 'multi-

\footnotetext{
52 De Keyzer, “All We Are”; de Keyzer \& Bateman, 'Late Holocene Landscape Instability’; Pierik et al., 'Controls.'

${ }^{5}$ Castel, Late Holocene Eolian Drift Sands; Ballarini et al., 'Optical Dating.'

${ }^{54}$ De Keyzer, "All We Are”; Pierik et al., 'Controls.'

55 Luterbacher et al., 'European Seasonal and Annual Temperature.'
} 
proxy' series. ${ }^{56}$ These series provide valuable information for efforts to detect the nature of regional climate variability and change; however, again, the use of more localized reconstructions should be prioritized where the focus of research is on hazards within a specific area, otherwise these may be obscured or dampened by regional averaging.

These discrepancies in data availability and the uncertainty that ensues should be considered when using such data. Even more crucial when exploring the hazard-society nexus, however, is the point that similar fluctuations in environmental conditions in two different societies do not always have the same impact for humans, or even for ecosystems. Often, there is low potential for disruption to societies - and accordingly it is essential to contextualize signatures of environmental variability found within 'natural archives,' something that can be done by integrating both documentary and non-documentary sources, where available.

\subsubsection{History and the Digital Age: Opportunities and Pitfalls for Historical Disaster Research}

The digital age has had major impacts on the ways in which historical data have been used. Only just over a decade ago, newly constructed quantitative historical datasets such as series of prices, mortality, and disease activity were usually found in appendices of books, and the scholars who used these data - or even knew of their existence - were typically historians. Today, many datasets are either published online with the original work or digitized from an older work and hosted on publicly available online repositories, which have led to increased visibility and availability of historical data. ${ }^{57}$ This has resulted in a wealth of opportunities for interdisciplinary scholarship into the human and environmental past. Indeed, there has been a surge of scientific interest in linking long-term human activity with environmental variability, with a new body of quantitative scholarship correlating the types of paleoclimatic data discussed in the previous section with historical data on human activity spanning the last millennium. This has led many to 'explain' human phenomena, such as conflict or disease incidence, as an outcome of climatic change. ${ }^{58}$

${ }^{56}$ Nash et al., 'Seasonal Rainfall Variability.'

${ }^{57}$ An example of the former: Brecke, 'Violent Conflicts.' An example of the latter: Büntgen et al., 'Digitizing Historical Plague.'

${ }^{58}$ See for example Zhang et al., 'Global Climate Change'; Zhang et al., 'The Causality Analysis'; Büntgen et al., '2500 Years of European Climate Variability'; Hsiang, Burke \& Miguel, 'Quantifying the Influence'; Zhang et al., 'Climate Change and War Frequency'; Tol \& Wagner, 'Climate Change and Violent Conflict.' 
While the very real and clear benefits of increasing accessibility of data cannot be understated, it is also important to consider what may be lost during the digitization process before historical information reaches its 'end state' as a data point that appears in a published online dataset. Such issues of source criticism are, of course, fundamental to historical research, but can go missing when old datasets are digitized and much of their contextual information is cast aside.

One such issue relates to the uneven collection and transcription of this material by scholars past and present. For example, many recently available online historical datasets are not new, but rely heavily on the work of individual scholars many decades ago. This can create spatial and temporal biases in data coverage as a result of the limited expertise and linguistic knowledge of individual scholars, or simply due to unequal access to archival material - particularly that outside of Western Europe. These problems have recently been identified in JeanNoël Biraben's original dataset on historical plague outbreaks, according to which the Low Countries appear to have been free of plague (Figure 3.3). However, a new inventory of data collected on plague outbreaks in the Low Countries shows that this was in fact not the case, but that this gap is a legacy of the work undertaken by one particular researcher. This demonstrates the need to adopt a critical approach to what may appear to be 'complete' datasets. At worst, such issues may bring into doubt the validity and robustness of high-profile studies on the causal factors behind historical plague outbreaks, susceptibility, and spread. $^{59}$

Digitized datasets are not limited to Europe. We have already seen the opportunities that colonial records can provide for explaining historical disasters and crises in non-Western societies, and, while such records may provide our only written sources of information at particular points in time, they must be subject to a particular type of scrutiny. One of the most frequently used historical datasets in studies linking climate and conflict incidence, for example, is Peter Brecke's global 'Conflict Catalog,' which was largely compiled from secondary published works. ${ }^{60}$ By Brecke's own admission, this dataset is an unfinished product, with errors "especially as we go back in time and into particular regions of the world." ${ }^{11}$ Coverage in the Southern Hemisphere - where data going back to 1400 have been used in various studies - is deficient before 1800, with most entries relating to conflicts between colonial powers and indigenous populations. Even where conflicts between indigenous populations do appear in the

${ }^{59}$ Roosen \& Curtis, 'Dangers.' $\quad{ }^{60}$ Brecke, 'Violent Conflicts.'

${ }^{61}$ Brecke, 'Notes Regarding the Conflict Catalog.' 


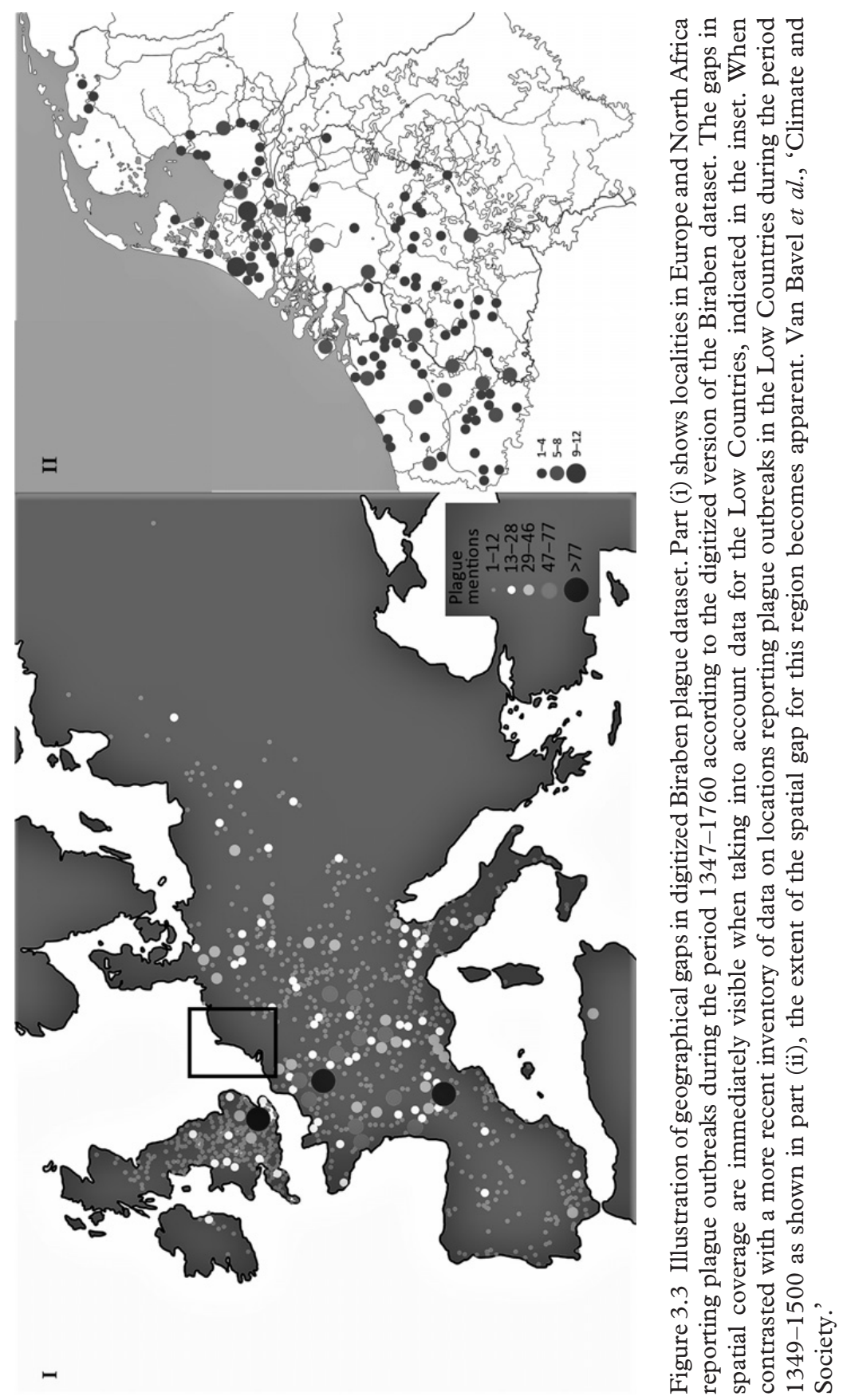


dataset, we also find issues. The widespread conflicts of the 1820 s in Southeast Africa, for example, are grouped into one decade-long conflict of the 'Zulu tribes,' a notion that dates back to early colonial writings which routinely exaggerated the effects of conflict, and in some cases even fabricated its existence. ${ }^{62}$ The number of fatalities assigned to this conflict $(60,000)$ is very likely based on interpretations of the same problematic sources that historians in Africa are reluctant to employ in their own studies, yet the sources on which these numbers, and indeed the whole dataset, are based are not made explicit. These criticisms are not to say that large datasets are to be discarded outside of Eurasia, but rather that new multidisciplinary efforts are needed to assess, add to, or create datasets that are based on region- and period-specific contextual knowledge, original sources rather than published works, and rigorous source critique.

As shown in recent work uncovering the history of plague in the Low Countries, historians have a major role to play in ensuring datasets are fit for purpose. This includes working with scholars from other disciplines to ensure appropriate selection, use, contextualization, and interpretation of historical data. At the very least, some key questions that should be considered before employing a historical dataset include the following.

1. Are the data geographically representative for the area(s) under consideration?

2. Is the temporal resolution of the data appropriate for the research question(s) under consideration?

3. Are the variables in the historical dataset representative of the phenomena under consideration? If not, what are the potential uncertainties?

4. Are the historical source types on which the dataset is based consistent, or do they vary? What uncertainties does variation in source types introduce?

5. How does the volume of historical source material vary over time? What uncertainties does this introduce?

Increasing specificity and transparency about uncertainty or potential biases in the data are part of the solution, though broader shifts in the publication process are also required. These could involve simple interventions like including historians as part of the peer-review teams, or more concerted efforts to develop open-access platforms through which to publish and access historical data. This would in turn incentivize historians to publish and refine datasets in a similar way to the natural sciences - the Geoscience Data fournal being just one example. Ultimately,

${ }^{62}$ Hannaford \& Nash, 'Climate, History, Society.' 
even with the most representative datasets, it is also incumbent upon scholars using these data to ensure that appropriate methodologies are selected, and it is to this issue that we turn next.

\subsection{Methodologies}

In this section, methodologies for historical disaster research are introduced, and the potential uses of the types of data described in the preceding section are demonstrated. This discussion of methodologies includes those employed in the reconstruction of hazards (e.g. droughts, floods, epidemics) and their impacts from historical sources, as well as analysis of human vulnerability, resilience, coping, and adaptation to these hazards. Crucially, this section stresses the importance of applying comparative methodologies over long temporal trajectories, which enables historians to move away from descriptive and event-focused approaches, although we also note how, in practice, this is not always straightforward to achieve.

\subsubsection{Hazard and Disaster Reconstruction from Historical Sources}

We have explored the types of historical documentary sources that can be used to study hazards and disasters, but how can we turn the information contained within these sources into systematic chronologies of hazard occurrence, characteristics, and impact where we lack instrumental records? Frequently the impact of hazards both past and present is couched in emotive language. An earthquake may be said to have 'decimated' Mexico City, or a tropical cyclone may be said to have 'devastated' the Mozambican coast, but to what extent can hazards and disasters be rendered comparable over space and time - and at what scales should we strive for such comparisons? In many areas, long and detailed chronologies of hazards have already been produced - particularly for source-rich regions such as Western and Central Europe. Reconstruction nevertheless remains an important part of interdisciplinary research in disaster history and its cognate subdisciplines of historical climatology and historical epidemiology. Indeed, sources previously unused for the study of disasters are still being brought to light, while improvements and innovations in reconstruction methods have allowed 'gappy' data to be used more robustly.

Documents containing abundant, regular, and systematic observations have, unsurprisingly, received most attention in the reconstruction of past hazards. One of the major reasons for this is that sources of this nature usually lend themselves to the application of statistical methods, 
especially where there is an overlap in observations of the same variable between historical documents and modern data. In turn, this allows for the calibration of statistical relationships between the recorded variable (e.g. wind direction) and the hazard to which it relates (e.g. precipitation), which can then be applied to historical data. ${ }^{63}$ This principle can apply to a range of historical sources, with perhaps the most famous example being harvest dates and temperature. ${ }^{64}$ In some regions, the inverse approach has been adopted, where paleoclimatic data on temperature have been used to reconstruct agricultural yields. ${ }^{65}$

In large parts of the Southern Hemisphere, the largely qualitative nature of historical documentary sources means that statistical methods are less suitable and other methods such as textual and content analysis need to be used. Typically, this means that a body of hazard-related quotations within a season or year is assessed against a quantitative scale. In the case of rainfall reconstruction from missionary accounts and private diaries, for example, such a scale might range from drought $(-2)$, dry $(-1)$, 'normal' $(0)$, wet $(+1)$ to extremely wet $(+2)$ relative to 'typical' rainfall levels. ${ }^{66}$ The resultant seasonal or annual values can then be combined to produce long-run time series of semi-quantitative climate data, which can be calibrated for accuracy in any overlap that exists with early instrumental series. Similar methods have been used to reconstruct cyclones, whereby qualitative descriptions of atmospheric conditions and of the extent of damage to buildings have been used as a proxy for cyclone intensity ${ }^{67}$ Even where observations on hazards are too sparse or scattered to reconstruct seasonal or annual variability in this way, however, they should not go to waste. We have already seen how historical observers tended to record those hazards which led to some form of societal impact. These subjective descriptions of climate-related hazards may be as important for the historian concerned with disasters as an 'objective' instrumental record, since disasters themselves are the product of human as much as environmental factors and are often subjectively defined phenomena. ${ }^{68}$

Moving beyond the reconstruction of hazards themselves, three main categories are accepted to measure the impact of a disaster: effects on people (death, injury, disease, and stress), effects on goods (property damage and economic loss), and effects on the environment (loss of flora and fauna, pollution, and loss of amenity). We will focus on the

\footnotetext{
${ }^{63}$ Hannaford, Jones \& Bigg, 'Early-Nineteenth-Century Southern African Precipitation.'

${ }^{64}$ Pribyl, Farming, Famine and Plague.

${ }^{65}$ Huhtamaa \& Helama, 'Reconstructing Crop Yield Variability.'

${ }^{66}$ Nash et al., 'Seasonal Rainfall Variability.' ${ }^{67}$ Nash et al., 'Tropical Cyclone Activity.'

${ }^{68}$ Hannaford, 'Long-Term Drivers'; Miller, 'The Significance of Drought.'
} 
use of mortality as an indicator in the following section. Mortality is by far the most dominant category employed to measure the impact of a disaster, and it gives us a clear insight into the challenges when it comes to measuring impact. Mortality is commonly at the center of thresholds and levels of minimal disruption used to identify and classify disasters. ${ }^{69}$ For example, the Centre for Research on the Epidemiology of Disasters (University of Louvain), which hosts one of the most extensive modern disaster databases, includes only those events with more than 100 deaths, as well as damages amounting to 1 percent or more of GDP, and the number of people affected as 1 percent of the total population. ${ }^{70}$

This type of assessment is, however, very much focused on physical damage and mortality, and excludes other important facets of disasters that we have discussed in Section 2.1. Another strategy is to define a perimeter that is hazard-dependent but uses a fixed threshold. Mark and Catherine Casson defined a crisis in terms of a deviation from an attested mean value - for example, rising mortality rates and soaring average food prices that progressed 20 percent beyond the normal average were deemed a crisis. ${ }^{71}$ This can, however, run into the same problems highlighted above, in that fixed values and thresholds cannot be applied to all hazards and are to some extent context-dependent. ${ }^{72}$ Other studies draw more directly from the concept of ecological resilience, defined as "the magnitude of disturbance that can be absorbed before the system redefines its structure by changing the variables and processes that control behavior." ${ }^{73}$ Often this is applied to ecosystems, but it has been used for societies and social institutions as well. With this definition, an event can be labeled a disaster when it redefines the structure and behavior of a society.

Mortality is an indicator of particular importance when reconstructing epidemic outbreaks - a trend that has been reignited in recent years with moves towards digitalization of data and GIS mapping. The sources necessary for reconstructing epidemics can be divided into two broad groups: direct documentary references or mentions of a disease that can be used as one form of 'diagnostic' evidence, or epidemiological evidence referring to the severity or spread of a disease, in its entirety or - preferably - differentiated by sex, age, and socio-economic status, as well as separating rural and urban data.

${ }^{69}$ See Section 2.2. $\quad{ }^{70}$ Smith, Keith \& Petley, Environmental Hazards.

71 Casson \& Casson, 'Economic Crises in England.'

${ }^{72}$ A point we will return to in Section 3.2.3.

${ }^{73}$ Gunderson, 'Ecological Resilience,' 426. See Section 2.3.4 for a detailed breakdown of the concept of resilience. 
Direct references to diseases can be found in various pre-modern sources, including burial registers, ordinances, wills, theological and medical treatises, bills of mortality, orphanage records, and city accounts. While these records can provide useful pointers to the dominant epidemiological conditions of a certain season or year, epidemiological information on a disease within such documents is not direct diagnostic information on what that disease actually was, and we should not always take the diagnosis of premodern contemporaries at face value. ${ }^{74}$ The term 'peste,' for example, may have referred to plague, but also may have been a 'catch-all' term to refer to all kinds of different afflictions that may have had features similar to plague. ${ }^{75}$ In Western Europe, it is often difficult to find a systematic distinction between diseases prior to the second half of the fifteenth century though in the early-modern sources this becomes much clearer. For example, scholars have been rather damning of what the burial records can directly say about cause of death, ${ }^{76}$ but in more recent times certain burial records have been shown to make very sharp distinctions between diseases - often with numerous terms used even in the same year. ${ }^{77}$ Nevertheless, even if pre-modern scholars, especially by the sixteenth and seventeenth centuries, could make broad distinctions between diseases, ${ }^{78}$ we still must accept that their diagnoses could be wrong - only DNA pathogen evidence can ultimately solve this. For some parts of the world, this lack of absolute confirmative evidence for what a disease actually was has led to substantial disputes: some scholars suggesting, for example, that plague did not substantially feature in pre-modern Japan, ${ }^{79}$ and it has been questioned whether the Chinese term 'wenyi,' broadly translated as plague, was actually the same disease caused by Yersinia pestis, ${ }^{80}$ even if we now have strong evidence that suggests the initial outbreak of the Black Death was linked to strains of the Yersinia pestis pathogen originating in the Qinghai Plateau of Western-Central China or southern Siberia. ${ }^{81}$

Mortality data also offer the opportunity to quantify the occurrence, spread, and severity of epidemics. In recent years there has been an attempt to quantify Black Death mortality rates across numerous localities within Europe. ${ }^{82}$ However, the source material behind this exercise is

${ }^{74}$ Cohn, Cultures of Plague; Carmichael, 'Universal and Particular.'

75 Theilmann \& Cate, 'A Plague of Plagues.'

76 Dobson, Contours of Death and Disease, 81.

${ }_{78}$ Curtis, 'Was Plague an Exclusively Urban Phenomenon?'

${ }_{78}$ As suggested in Cohn, Cultures of Plague.

${ }^{79}$ Bowman Jannetta, Epidemics and Mortality.

${ }^{80}$ Dunstan, 'The Late Ming Epidemics'; Cao \& Li, Shuyi.

81 See the classic Cui et al., 'Historical Variations.'

${ }^{82}$ Christakos et al., Interdisciplinary Public Health Reasoning; Voigtländer \& Voth, 'The Three Horsemen'; Gómez \& Verdú, 'Network Theory.' 
invariably not epidemiological. It consists of estimates of mortality impact by contemporary observers from all kinds of disparate sources, which, in truth, are difficult to compare. More reliable epidemiological indicators come from sources which have roughly consistent features between localities and even over time, and, of course, exist for a large number of localities - mortmain accounts and church burial records being two of the main examples, although one problem has been that material for epidemiological reconstructions over large areas and long periods is not as readily available for the late Middle Ages. ${ }^{83}$ Methodologically, obtaining mortality rates from these data sources is problematic as these require either recorded population estimates or highly sophisticated numerical models in order to produce the information. For England, the latter have been developed by the Cambridge Group for the History of Population and Social Structure, and are expounded at length in the Population History of England. ${ }^{84}$ Other methods beyond simply listing the total numbers of burials have also been used. An example that has regained popularity is one originally developed by the Italian demographer Massimo Livi Bacci, whereby relative annual mortality is calculated on the basis of the percentage increase or decrease in burials from preceding years, offering insight into the severity and spread of mortality across different localities and regions. ${ }^{85}$ Because an increase in burials to a level 50 percent or more higher than in previous years has been suggested to have prevented the generation born in a given year from replenishing the population, this threshold has been used as a sign of crisis or disaster. ${ }^{86}$ Two of the major advantages of this method are that it requires no data other than the burial records themselves, and is amenable to relatively straightforward calculations and processing. Analysis of seasonal distributions of burials can also give insight into causes of death, which may include famine as well as disease. Age and gender may offer further clues, although, given the uncertainties around the age and gender characteristics of some diseases, one should be careful to avoid circular reasoning here.

\subsubsection{Vulnerability Assessment}

A vulnerability assessment analyses how exposed certain individuals or groups are to a particular hazard. It tracks the potential population at risk and tries to explain the social structures, economic behaviors,

\footnotetext{
${ }^{83}$ For a discussion of these sources, see Section 3.1.1.

${ }^{84}$ Wrigley \& Schofield, The Population History.

${ }^{85}$ Roosen \& Curtis, 'The "Light Touch"'; Alfani, 'Plague in Seventeenth-Century Europe'; Curtis, 'Was Plague an Exclusively Urban Phenomenon?'; Curtis \& Dijkman, 'The Escape from Famine.'

${ }^{86}$ Alfani, 'Plague in Seventeenth-Century Europe.'
} 
institutional conditions, and physical circumstances that determine the exposure to hazards and the ability to recover from their occurrence. Sometimes vulnerability is identified simply through the occurrence of disaster, but this is problematic: at least in theory, vulnerability may exist irrespective of whether a disaster occurs, even if in practice the underlying patterns may be revealed only when disaster does strike.

One way to unravel - although not formally assess - vulnerability is suggested by the Pressure and Release (PAR) model developed in disaster studies. ${ }^{87}$ This model aims to explain how the interaction of vulnerability, on the one hand, and the occurrence of hazards, on the other, may lead to disaster. In the process, it also unpacks the concept of vulnerability. The 'pressure' component of the model distinguishes three levels of underlying factors. At the base are 'root causes': economic, social, and political conditions that affect the distribution of power and resources. 'Dynamic pressures,' such as rapid urbanization, economic depression, or war, may transform these root causes into the 'unsafe conditions,' such as settlement in hazard-prone locations or unhealthy living quarters, that are the ultimate expression of vulnerability. The concepts of root causes, dynamic pressures, and unsafe conditions have also been used as a lens through which vulnerability in case studies of historical disasters can be explained. ${ }^{88}$

A more formalized assessment of vulnerability has also gained currency within contemporary fields such as development or climate studies. This typically draws upon quantitative social research methods such as household surveys, or may involve the analysis of larger economic datasets. A common approach is the use of indicators. This involves the identification of a series of indicators associated with exposure, sensitivity, and adaptive capacity to a particular hazard, independently of the occurrence of the hazard itself. ${ }^{89}$ These indicators can be based upon links established from a range of general and context-specific literature, for example that diversity in cultivated crops reduces sensitivity to drought, or that grain storage enhances adaptive capacity. Other indicators may be more subjective, where, for example, the integration of pre-colonial African communities within intercontinental trade networks on the one hand provided a potential source of grain in times of scarcity, but on the other hand subjected these communities to exploitation. Indicators are usually clustered in a limited number of relevant dimensions and subsequently translated into an index. Typically, indicators are given a value that represents a positive or negative contribution to vulnerability. These

87 Blaikie et al., At Risk, 24.

88 Barnes, 'Social Vulnerability and Pneumonic Plague'; Soens, 'Resilient Societies.'

${ }^{89}$ Hinkel, "Indicators of Vulnerability”; Füssel, 'Vulnerability'; Hahn, Riederer \& Foster, 'The Livelihood Vulnerability Index.' 
values may be weighted according to those components adjudged to contribute the most to vulnerability, or they may simply be given equal weight. The result can be a snapshot of vulnerability at a particular point in time for a particular locality or social group, but it is also possible to make temporal or spatial comparisons by including multiple localities, regions, or time periods in the analysis.

Although in historical research assessment of vulnerability is usually less formalized and frequently qualitative in nature, indicator analyses have recently been applied to various historical contexts, notably the Irish famine of $1740-41,{ }^{90}$ climate anomalies in Iceland and the Eastern United States during the first and second millennia $\mathrm{AD},{ }^{91}$ and drought in Southeast Africa between the sixteenth and nineteenth centuries. ${ }^{92}$ This range of contexts demonstrates the particular value of indicator approaches in areas where sources - which may also be archaeological or zooarchaeological - are fewer in number but are of sufficient breadth to capture the multidimensional nature of vulnerability. Where documentary sources are greater in number, the information available on one indicator (e.g. wages) may go far beyond that available for a whole cross-section of indicators in other contexts, and so the use of indicators may be a less suitable approach. There is also a difficulty in integrating cultural norms and religious beliefs into indicator assessments, which can render them somewhat twodimensional. Thus, while indicator approaches provide a useful comparative tool, the results should generally be seen as points of departure that seek to simplify a complex reality rather than end-states of analysis.

Whichever way vulnerability is analyzed, in historical perspective we can find merit in considering vulnerability as the 'flipside' of adaptation that is to say, vulnerability and adaptation are co-evolving, interdependent phenomena. ${ }^{93}$ Bringing adaptation into the discussion also calls for an analysis of institutional responses and the social actors behind these responses. We have already seen how responses to hazards and disasters are not necessarily 'rational' or equivalent to the 'common good,' and this is where qualitative analysis of institutional records of a narrative nature can provide an invaluable counterpart to analysis of both pre-existing vulnerabilities and hazard and disaster outcomes. This allows us to bring into view the importance of contingency, social actors, and environmental knowledge in human-environment interactions over time, while also helping us avoid linear or teleological success narratives of adaptation as 'improvement.'

\footnotetext{
${ }^{90}$ Engler et al., 'The Irish Famine.' $\quad{ }^{91}$ Nelson et al., 'Climate Challenges.'

${ }^{92}$ Hannaford, 'Long-Term Drivers.'

${ }^{93}$ See arguments made in Rohland, 'Adapting to Hurricanes.'
} 


\subsubsection{Comparative Methodologies}

This chapter started out by pointing to the importance of comparative analysis. Before we expand on how this can be done, we must first consider why it is necessary and the problems associated with some of the other approaches that have been prominent in historical research on disasters over recent decades. These approaches are linked to the move that the historical profession has made away from the social sciences, resulting in the situation where historians are less likely to subscribe to the view that the past can be used to establish regularities, patterns, and certainly not laws, through comparative analysis. This has been driven in part by a fear of accusations of being 'deterministic,' therefore privileging events and the narrative, and perhaps even a situation where poststructuralists would offer up the past as an "undecidable infinity of possible truths." ${ }^{94}$ For the specific study of historical disasters, there are a number of drawbacks to this present situation of the historical profession.

First, a focus on events, as in histoire événementielle or evental history, can lead to over-emphasis or over-exaggeration of certain features within these 'special cases' that are then said to apply more broadly for other hazards and the disasters that can ensue. For example, the notion that epidemics inevitably caused societies to descend into scapegoating and persecution of easily targeted groups has undoubtedly been connected to scholars focusing in on just a few very spectacular cases such as the Black Death or AIDS - which have proven to be anomalies when placed within a broader temporal and geographical perspective of all social responses to epidemics. ${ }^{95}$

Second, over-emphasis on one disaster can lead to the privileging of certain theoretical or explanatory frameworks over others. For example, for the medieval period, an exceptional amount of focus has gone into the famine of 1315-17 in isolation, which is problematic in the sense that this famine occurred - at least in a European context - within very special social and environmental conditions that were probably not to be repeated across the whole of the pre-industrial period to the same extreme. That is to say, the famine of 1315-17 in many parts of Northern Europe occurred in conditions of unparalleled population pressures on resources - thus being an exceptional event - but not one representative of all the famines that occurred throughout the medieval and early-modern periods. ${ }^{96}$ As yet, few attempts have been made to compare, for example, the famine experience of localities in conditions of high Malthusian

${ }^{94}$ All discussed in Curtis, van Bavel \& Soens, 'History and the Social Sciences.'

95 Cohn, Epidemics. $\quad{ }^{96}$ A problem highlighted in Geens, 'The Great Famine.' 
pressures with the famine experience of localities with low Malthusian pressures. Similar concerns over the representativeness of historical hazards chosen by scholars have recently been iterated by historians and archaeologists focusing on late-medieval earthquakes in the Mediterranean. ${ }^{97}$

Third, this can also lead to the problem of over-emphasizing a conspicuous feature of a society hit by a disaster as possible causal factor. Quite often, at least in studies focusing on the twentieth and twenty-first centuries, the factor that is often cited is 'poverty' - by way of description or inductive reasoning - and this feeds into narratives that see the 'Global South' as a disease-ridden, inhospitable place - povertystricken and disaster-prone in equal measure. ${ }^{98}$

One of the positive developments in recent years in the study of historical disasters is the greater tendency towards assessing hazards and shocks, and the disasters that can ensue, in a much broader geographical and temporal perspective - that is to say, we are moving in a more global direction. Recent literature has warned us of over-focusing on the Black Death, and trying to apply abstract theoretical models of redistribution or economic development based on the logical mechanisms connected to this 'anomalous' shock. ${ }^{99}$ Scholars are now assessing the Black Death within its place in the broader chronology of the Second Pandemic over five centuries. ${ }^{100}$ In line with broader movements in the discipline of history, scholars have also moved in more recent times to challenge Eurocentric conceptions of the Black Death, instead using new kinds of global data sources - particularly from bioarcheology and genome analysis - to reveal its truly global effects and consequences. ${ }^{101}$ On the subject of famines, recent literature too has moved away from looking only at very severe cases such as the 1315-17 Great Famine. Instead, it considers how food crises and famines developed in regions across the whole pre-modern period - comparing some of their features, causes, and consequences in a more standardized way. ${ }^{102}$ Furthermore, we have come to the realization that a terrible event etched in popular consciousness such as the Great Famine of Ireland in the middle of the nineteenth century was not a catastrophe for Ireland in isolation, but part of a broader problem affecting much wider geographical territories - and

${ }^{97}$ Forlin, Gerrard \& Petley, 'Exploring Representativeness and Reliability.'

${ }^{98}$ Frerks \& Bender, 'Conclusion,' 199.

99 Alfani \& Murphy, 'Plague and Lethal Epidemics.' 100 Cohn, 'Patterns of Plague.'

101 The special issue of The Medieval Globe edited by Monica Green, Pandemic Disease, https://scholarworks.wmich.edu/tmg/vol1/iss1/. Also see Green, 'Black as Death.'

102 Alfani \& Ó Gráda (eds.), Famine; Collet \& Schuh (eds.), Famines during the 'Little Ice Age.' 
that the excessive focus on events such as those in Ireland is entrenched in historiographical traditions. ${ }^{103}$ Scholars are also now interested in placing earthquakes in broader geographical and temporal frameworks. For a long time earthquakes were the subject of analysis as isolated events, and most comparative approaches were limited to those interested in paleoseismological aspects of earthquakes - resulting in mere catalogs of seismic events. ${ }^{104}$ Recent research has looked to add to that approach by elaborating upon similarities and differences between Mediterranean late-medieval and early-modern societies in coping with and preparing for earthquakes. ${ }^{105}$

There are, however, practical challenges to employing comparative approaches - which are applicable for the discipline of history as a whole, but with even greater relevance for the study of historical disasters. As we have seen in the previous sections of this chapter, the first issue is that historical source material is a fickle substance, distributed unevenly across time and space. Even when sources are relatively abundant, they are often difficult to interpret and reveal only small segments of the phenomenon under investigation. ${ }^{106}$ This can be demonstrated in the study of the redistributive effects of disasters for dimensions such as wealth and property. Each source for reconstructing inequality has its own idiosyncrasies - differing methods of calculation, recording, and exclusion rates - which mean that it is difficult to compare the redistributive effects of disasters between regions or localities in any absolute terms. Some scholars have conceded this and suggested that these kinds of sources can be used only in very relative terms - measuring the redistributive effects of shocks such as epidemics or floods in the same localities or regions over time using the very same type of source. ${ }^{107}$ Indeed, we have come to realize that it is in the temporal dimensions of comparison that trained historians have considerable advantages and can provide added value when trying to understand the causes and consequences of disasters. Another source-related problem connected to comparative approaches is the simple issue of their complete absence - or rather random appearance over time. In keeping with the same example of redistribution, the problems can be seen in Walter Scheidel's The Great Leveler on the redistributive impact of terrible mortality shocks and

103 See the essays in Ó Gráda, Paping \& Vanhaute (eds.), When the Potato Failed.

${ }^{104}$ For a selection of online catalogues see www.bgr.bund.de/EN/Themen/Seismologie/E rdbebenauswertung_en/Kataloge_en/historisch/historische_erdbeben_inhalt_en.html

105 Forlin \& Gerrard, 'The Archaeology of Earthquakes.'

106 Curtis \& Roosen, 'On the Importance of History.'

107 Alfani \& Ammannati, 'Long-Term Trends in Economic Inequality'; van Bavel, Curtis \& Soens, 'Economic Inequality.' 
outbreaks of violence. ${ }^{108}$ The only empirical study cited in Scheidel's book that actually has this very specific kind of systematic information for the pre-industrial period (immediately before and after a shock) concerns one town in Northern Italy in the seventeenth century. ${ }^{109}$ Put simply, throughout history, we have very few occasions where we have an empirically measurable record for distribution just before a disaster and then just after a disaster, and it is even rarer to have both of those (which would be necessary for assessing direct short-run effects) and then a long-term series of the same information. This reduces our confidence in the posited causal links between, for example, 'leveling' and catastrophic shocks. And this does not merely apply to redistribution but to a whole raft of social indicators - the same problems can be posited for the effects of disasters on age of marriage, for example. ${ }^{110}$

A second problem explicitly related to the subject of historical disasters is that it is very difficult to apply systematic social science methods: an obvious one being to hold a number of variables constant as much as possible, in order to isolate those that are held to be crucial and are tested for. Although the geographical and temporal scope of our comparisons has broadened with regard to historical disaster studies, ${ }^{111}$ systematic comparative approaches lag some way behind. In his discussion of social science concepts and comparative methods, Giovanni Sartori noted that "If two entities are similar in everything, in all their characteristics, then they are the same entity. If, on the other hand, two entities are different in every respect, then their comparison is nonsensical." ${ }^{112}$ Disaster studies scholars have to work more on reducing the number of variables - one of the most important components of successful comparative research - if they are going to get closer to answering important social science questions such as why some societies cope more effectively than others with hazards. The problem here is that quite often we are comparing different hazards, or at least different magnitudes and intensity of the same type of hazard, at the very same time as comparing different societal variables of possible importance. ${ }^{113}$

This issue can be demonstrated by focusing on just one typical kind of failure in this regard: for example, in the comparison undertaken between two floods occurring in 1993 and 1994 in two different

108 Scheidel, The Great Leveler.

109 Investigated by Alfani, 'The Effects of Plague.' See also Curtis, 'All Equal in the Presence of Death?'

${ }^{110}$ See Section 6.1.1. ${ }^{111}$ See the recent Schenk (ed.), Historical Disaster Experiences.

112 Sartori, 'Comparing and Miscomparing,' 246.

113 As argued at length in van Bavel \& Curtis, 'Better Understanding Disasters.' 
countries - in Northwest Italy and the US Midwest. ${ }^{114}$ In conclusion the author suggests that very divergent 'human responses' to the floods were connected to essential differences between the afflicted societies in terms of socio-political traditions and organization and levels of integration within communities. This may, of course, prove to be correct, but the argumentation is overshadowed by the fact that we are never sure what impact the differing magnitude and scale of the respective floods had on societal responses. It thus becomes difficult to separate factors at the local or national level, and it is unclear what differences exactly played a crucial role in light of the numerous differences between these two societies. What could have been more illuminating is to take the research one stage further and compare responses of different localities within either the US Midwest or Northwest Italy - limiting the number of possible independent variables and thus being more able to hold the hazard constant. In fact, this is where the pre-industrial period actually has some advantages over these kinds of modern studies because, on a regional and even local level, small-scale societies which were very close to each other (separated by just tens of kilometers) could have very divergent economic and agricultural organization, microdemographic regimes, and patterns of tenure and resource distribution, among other factors. ${ }^{115}$ Very different societies close to each other and exposed to the same exogenous pressure can be identified - a good example being the regional comparison of different plantation economies dealing with the eruption of Mount Soufrière in 1812 on the island of St. Vincent, and actually showing very divergent rates of recovery. ${ }^{116}$ Furthermore, this is generally something far easier to find in the historical context than for the twenty-first century - particularly in the 'developed' world, where these differences have become less sharp under the homogenizing forces of modern commerce, the rise of nation states, improved transport, and better communication.

Smaller-scale comparisons over longer periods of time offer a way forward for comparative approaches into historical disasters, and that in itself may bring with it new opportunities for other kinds of comparisons often within the same individual localities or communities themselves. This can be across many dimensions which are often underexplored in the historical context - the differential impact of a disaster occurring within the same locality over time between men and women, adults and children,

\footnotetext{
114 Marincioni, 'A Cross-cultural Analysis.'

115 Curtis, Coping with Crisis; van Bavel, Manors and Markets.

116 Smith, 'Volcanic Hazard in a Slave Society.'
} 
the healthy and the frail, the rich and the poor, and recent migrants and (so-called) natives. Smaller-scale comparisons may also avert some of the problems relating to disparities in source types and availability that come with larger-scale comparisons. There is still a great scope for analytical, smaller-scale comparative work on historical disasters. 